\title{
CORRELATION BETWEEN EMOTIONAL INTELLIGENCE OF YOUNG PEOPLE AND THEIR ACADEMIC ACHIEVEMENT: EMPIRICAL PROOF
}

\author{
Rosita Lekavičiené $\dot{1}^{1}$, Dalia Antiniené⿱2 \\ Kaunas University of Technology', Kaunas, Lithuania \\ Lithuanian University of Health Sciences ${ }^{2}$, Kaunas, Lithuania
}

\begin{abstract}
Background. A scientific problem concerning factors which are important for academic achievement of students is analysed in the paper. Questions whether emotional intelligence level is related to academic achievement and whether correlation between academic achievement in a specific area (science, languages) and EI expression exists, whether emotional intelligence of young people with low education differs from that of young people with higher education, etc. are raised.

Methods. Research participants were 1430 students aged between 17 and 27 years. The survey was performed using EI-DARL V2 test. The following factors were assessed: "Perception of one's own emotions"; "Control of one's own emotions"; "Perception of emotions of other people"; "Control of emotions of other people", and "Manipulations". Also, such aspects as ability of recognizing emotions in facial pictures and ability of emotional situation solving were assessed.

Results. The combined EI scale scores in all factors were the highest of those subjects who are or were excellent students, the lowest - of those who were poor students. Those subjects who were equally poor both at languages and sciences were the least capable of perception of their own emotions and those of others people, they also were the least capable of controlling their own emotions. Highly educated young people were of higher emotional intelligence. Furthermore, emotional situation solving and emotion recognition in pictures was better in the group of highly educated students.

Conclusion. Positive correlation between academic achievement and emotional intelligence was established. Mathematics and language skills proved to be significant indexes of emotional intelligence: it was established that those subjects who were more successful in sciences were the best at understanding and controlling their own emotions, while individuals who were better in languages were more efficient in understanding and controlling emotions of other people.
\end{abstract}

Keywords: academic achievement, educational level, emotional intelligence.

\section{INTRODUCTION}

$\mathrm{N}$ umerous studies are performed in the world aimed at naming factors important for academic achievement. The need for such studies is understandable: having identified and corrected both internal personality and external environment factors it would be possible to expect higher academic achievement and later - professional success. In this context, for example, Lillydahl (1990) examined social and economic factors; Bjarnason (2000) explored the importance of relations with peers, etc. Studies that aimed at searching correlations between emotional intelligence (EI) and academic achievement may also be attributed to the said category. The question is raised whether EI improves individual performance (including academic). Scientists are not unanimous on this issue; independent, systemic proof is lacking. Some researchers present data that 
EI is not related or very weakly related to results of cognitive origin (Mavroveli, Petrides, Sangareau, \& Furnham, 2009; Mavroveli \& Sánchez-Ruiz, 2011; Petrides, 2011; Radford, 2011; Suliman, 2010). Supporters of the other view maintain that EI does have influence on academic achievements, especially when the level of academic assignments exceeds cognitive resources of the personality and when high academic results have to be demonstrated in stressful situations (Fallahzadeh, 2011; Ferrando et al., 2010). This view is substantiated by the fact that individuals with highly developed EI are able to identify and control their own emotions and those of other people, they are less affected by fear and other negative emotions - all factors that negatively affect individual and team performance (Seipp, 1991). Therefore, heterogeneous results show that there is a need to continue such research while taking into account methodological aspects of studies.

The purpose of the present article is to reveal correlation between emotional intelligence and academic achievement of young people. The following tasks were solved in the research: 1) correlations between school knowledge subjectively assessed by the subjects and EI factors were determined, 2) possible correlation between achievement in a certain study field and EI factor expression was looked for, 3) existence of differences between EI factor expression of young people of low and high education level was sought.

\section{METHODS}

Subjects. A total of 1430 subjects were interviewed. The study involved young studying, employed people, also the unemployed, involved in various community and political organizations and even imprisoned individuals. The target group was young people from 17 to 27 years of age $(M=19.7$, $S D=3.29) ; 43.2 \%$ of men and $55.5 \%$ of women participated in the survey $(1.3 \%$ did specify their gender). A total of 1092 subjects who were studying were surveyed: secondary school and gymnasium students of $11-12$ grades $(n=371)$, vocational school $(n=384)$, college $(n=158)$ and university $(n=399)$ students. Other interviewed persons were the unemployed ( $n=15)$; imprisoned young people $(n=54)$, representatives of some unions and social movements: young liberals $(n=11)$, scouts $(n=7)$ and others.

Instruments. The survey questionnaire consists of two parts. The first part is dedicated to assessment of personality EI level applying EI-DARL V2 methodology (Antinienè \& Lekavičienè, 2014; Lekavičienė \& Antinienè, 2014). Assessments are made in the following scales: "Perception of one's own emotions"; "Control of one's own emotions; "Perception of emotions of other people"; "Control of emotions of other people" and "Manipulations". The statements of the manipulation scale are aimed at detecting the person's ability to control the behaviour of people around them by using their emotions, discovering their weaknesses. In addition to the said scales such EI expression aspects as ability to recognize emotions in pictures (the identification scale of facial expressions) and ability to solve emotionally loaded social situations (the scale of emotionalsocial and interpersonal situations) were assessed. The psychometric quality of the instrument is sufficient.

In the second part of the questionnaire questions regarding demographical and psychosocial characteristics of the subject: age, sex, socioeconomic status, present occupation, etc. were presented. Questions about academic achievement of young people were also presented in this part of the questionnaire.

\section{RESULTS}

Correlation between subjectively assessed their own school knowledge and EI factors of subjects. Subjects were asked to assign themselves to a group of excellent, good, average, and poor students by grades that they received at school. The results of study showed that emotional intelligence (i.e., combined in all factor scales) was the highest of those subjects who were excellent students, while the lowest - of poor students $\left(\chi^{2}=11.53\right.$, $p \leq .01)$. High emotional intelligence also statistically significantly correlated with excellent or good academic achievement in the following scales: "Control of one's own emotions" $\left(\chi^{2}=11.82\right.$; $p \leq .01)$, "Understanding of emotions of other people" $\left(\chi^{2}=25.57 ; p \leq .0001\right)$, and "Control of emotions of other people" $\left(\chi^{2}=15.91\right.$; $p \leq .001)$. Table 1 shows relation between academic achievement and EI level in more detail.

Analogous results were obtained in emotionalsocial situations and face recognition scales. Excellent at present or in the past students were the best in situation solving (Mean Rank $=503.28$ ), poor students (at present or in the past) showed the worst results (Mean Rank $=251.00)\left(\chi^{2}=87.17\right.$, 


\begin{tabular}{|l|c|c|c|c|}
\hline \multicolumn{1}{|c|}{ EI Scales } & $\begin{array}{c}\text { Combined EI } \\
\text { Assessment of } \\
\text { Academic Achievement }\end{array}$ & $\begin{array}{c}\text { "Control of } \\
\text { one's own } \\
\text { emotions" }\end{array}$ & $\begin{array}{c}\text { "Understanding } \\
\text { emotions of other } \\
\text { people" }\end{array}$ & $\begin{array}{c}\text { “Control of } \\
\text { emotions of } \\
\text { other people" }\end{array}$ \\
\hline $\begin{array}{l}\text { Excellent student (used to get } \\
\text { grades 10-9) }\end{array}$ & 499.67 & 643.14 & 644.73 & 675.25 \\
\hline $\begin{array}{l}\text { Good student (grade 8 was } \\
\text { predominant, sometimes would } \\
\text { get 7) }\end{array}$ & 488.43 & 571.52 & 676.27 & 690.10 \\
\hline $\begin{array}{l}\text { Average student (mostly would } \\
\text { get 7 and 6) }\end{array}$ & 434.08 & 557.69 & 561.43 & 599.98 \\
\hline $\begin{array}{l}\text { Poor student (mostly would get 5, } \\
\text { 4 and lower) }\end{array}$ & 394.17 & 541.90 & 554.79 & 595.41 \\
\hline
\end{tabular}

Table 1. Duplex model of subjective assessment of one's own academic achievement and emotional intelligence factors. Kruskal-Wallis Test mean ranks

\begin{tabular}{|l|c|c|c|c|}
\hline \multicolumn{1}{|c|}{ EI Scales } & $\begin{array}{c}\text { "Understanding } \\
\text { one's own } \\
\text { Study }\end{array}$ & $\begin{array}{c}\text { "Control of } \\
\text { omotions" } \\
\text { emotions" }\end{array}$ & $\begin{array}{c}\text { "Understanding } \\
\text { emotions of other } \\
\text { people" }\end{array}$ & $\begin{array}{c}\text { "Control of } \\
\text { emotions of } \\
\text { other people" }\end{array}$ \\
\hline $\begin{array}{l}\text { I was better at sciences in } \\
\text { school }\end{array}$ & 623.61 & 611.11 & 579.06 & 587.69 \\
\hline $\begin{array}{l}\text { I was better at languages in } \\
\text { school }\end{array}$ & 580.26 & 560.15 & 682.38 & 711.70 \\
\hline $\begin{array}{l}\text { I was equally successful in both } \\
\text { areas in school }\end{array}$ & 604.18 & 596.94 & 612.53 & 651.18 \\
\hline $\begin{array}{l}\text { I was equally poor in both areas } \\
\text { in school }\end{array}$ & 464.62 & 485.30 & 559.26 & 598.74 \\
\hline
\end{tabular}

Table 2. Duplex model of components of academic achievement in a specific area assessment and emotional intelligence. Kruskal-Wallis Test mean ranks

$p \leq .0001)$. Similarly, excellent students were the most successful in emotional state recognition in faces (pictures) (Mean Rank $=359.54$ ) while poor students showed the worst results (Mean Rank $=$ 279.74, $\chi^{2}=20.47, p \leq .0001$ ).

Correlation between academic achievement of subjects in a specific area and EI factors. In the questionnaire subjects were also asked to specify in what areas of studies - sciences (mathematics, physics, IT, etc.) or languages (native, foreign) they were more successful; furthermore, two additional choices were presented - "I was equally successful in both areas" and "I was equally unsuccessful in both areas".

It was established that those who were better at sciences were best at understanding and controlling their own emotions: understanding score $\chi^{2}=87.17(p \leq .0001)$, controlling score $\chi^{2}=$ $87.17(p \leq .0001)$, whereas individuals who were more successful at languages were more efficient in understanding and controlling emotions of other people: understanding score $\chi^{2}=87.17(\mathrm{p} \leq .0001)$, controlling score $\chi^{2}=87.17(p \leq .0001)$. Table 2 shows the relation of academic achievement in a specific area with EI level in more detail.

Table 2 shows that those subjects who were equally poor both at sciences and languages were the worst in understanding their own emotions and those of other people. However, it is interesting to note that those subjects who were excellent at sciences were the worst in controlling emotions of other people.

Expression of EI factors of young people of low and high education level. Subjects hypothetically formally were allotted into two levels by the type of their activity: vocational school students, jobless, and imprisoned subjects were assigned to the low education group; gymnasium seniors, college and university students, and active young people working in various youth organizations were assigned to the high education group.

Cumulative percentage frequency probability distribution was applied to group comparison. Cumulative frequency curves show group differences in an informative and telling way (see Figure 1). Analogous statistically significant differences were also obtained by individual EI scales.

It has to be noted that particularly big differences between different educational level groups were observed in social-emotional situation solving (see Figure 2); statistically significant differences were also recorded in facial emotion recognition (see Figure 3). 


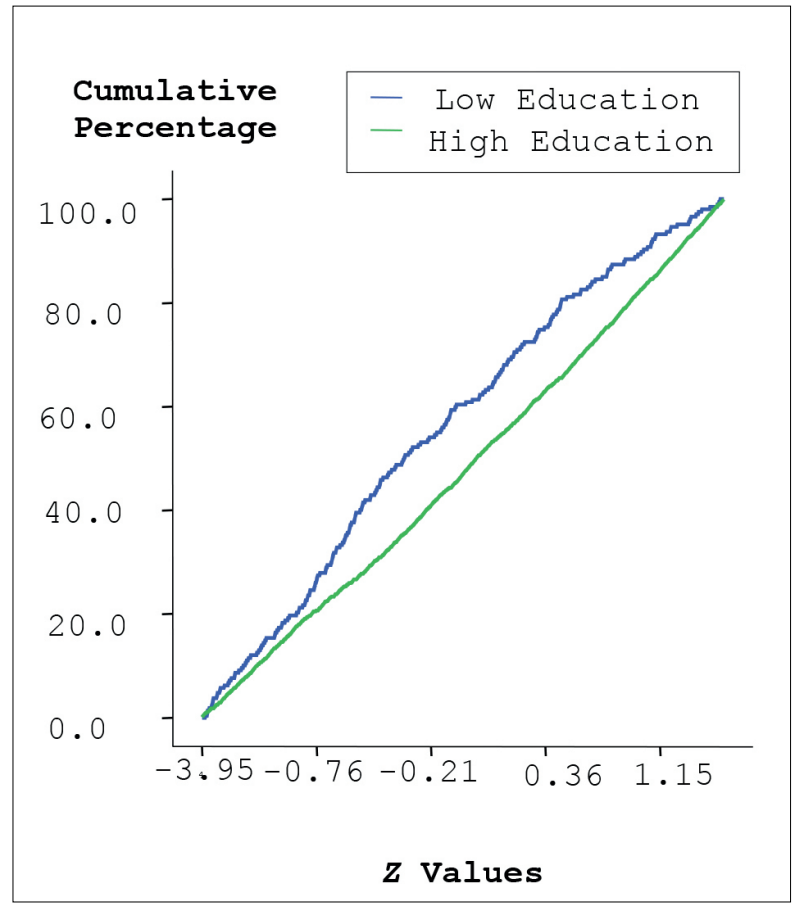

Figure 1. Comparison of Combined EI Scale and scores of low and high education subjects

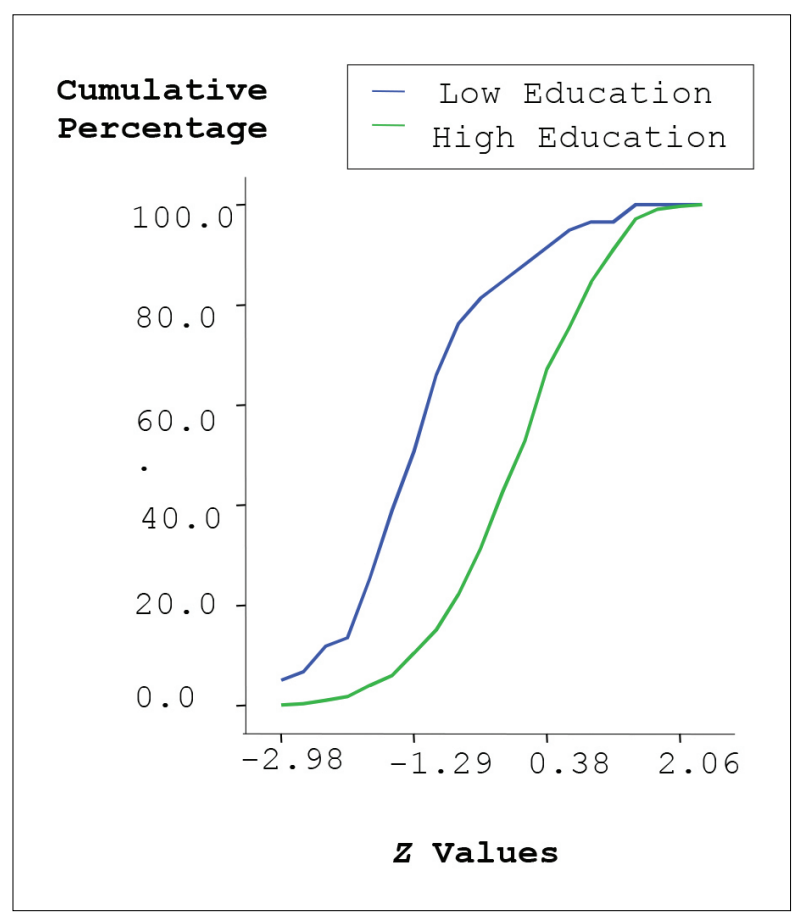

Figure 2. Comparison of low and high education subject scores in Social-Emotional Situation Solution Scale

Calculation of Mann-Whitney criterion $U$ showed that statistical solutions satisfied very strict reliability condition $p \leq .0001$.

It was established that young highly educated people were of higher emotional intelligence ("Combined EI Scale") (Mean Rank $=474.46$ ) than poorly educated (Mean Rank $=395.32$ ).

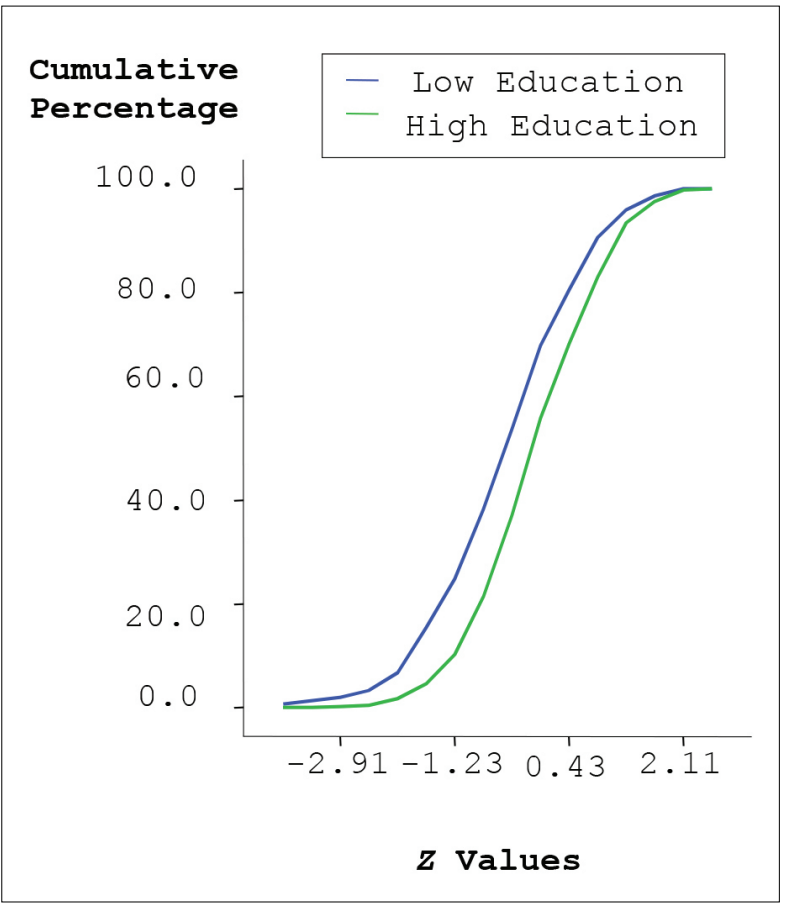

Figure 3. Comparison of Facial Emotion Recognition (in pictures) Scores of low and high education subjects

Individuals of higher education were better at understanding and control emotions of other people (understanding Mean Rank $=530.85$, control Mean Rank $=553.39$ ). The same applies to understanding and control of their own emotions: high education (understanding Mean Rank $=573.88$, control Mean Rank $=553.39)$, low education - understanding Mean Rank $=510.96$, control Mean Rank $=493.85$.

It was also established that solutions of socialemotional situations were better in the group of people with higher education (Mean Rank $=419.40$ and Mean Rank $=410.73$ in the first and the second cases correspondingly) than in the group of people with lower education (Mean Rank $=175.06$ and Mean Rank $=201.07$ in the first and the second cases correspondingly). Emotion recognition in faces (pictures) was also more successful in the group of people with higher education, Mean Rank $=322.06$, while in the group of people with low education it was less successful - Mean Rank $=250.39$. In this case, it was the same as in social situation solution, $p \leq .0001$.

\section{DISCUSSION}

The obtained research results have confirmed existence of positive correlation between EI level and academic achievement. They concur with correlation between EI and academic achievement 
confirmed by foreign scientists (Barchard, 2003; Codier \& Odell, 2014; Fallahzadeh, 2011; Ferrando et al., 2010; Lam \& Kirby, 2002; Petrides, Frederickson, Furnham, 2004; Zins, Weissberg, Wang, Walberg, 2004, and other). Review of articles of this type has shown that determined correlation between EI and academic achievement usually range between 0.20 and 0.30 , however, sometimes more impressive data may be found, e.g. Fayombo (2011), having surveyed 151 students $(M=23.0, S D=7.6)$ determined very firm correlation between EI and academic achievement $(r=.439$, $p<.05$ ). Meta-analysisofempiricalstudies of thistype performed in 1998-2012 by Perera and DiGiacomo (2013) is even of greater value than individual studies. Studies, in which academic achievement was assessed objectively (grade average, standardized academic test scores, knowledge of subjects) or subjectively (by self-evaluation), were selected. Analysis of 48 independent cases encompassing approximately 8700 survey subjects revealed that correlation between EI and academic achievement had reached $r=.30$. Furthermore, an important observation has been made that correlation between EI and academic achievement is more obvious in primary school $(r=.28$, $p<.05)$ and less obvious at university level $(r=.18$, $p<.05)$. How could analogous results presented in the article and obtained by other authors be used practically?

As the evidence that higher EI should be related with higher individual cognitive achievement increases, this should encourage the creation and implementation of EI development programs in educational facilities. Scientists not only maintain that such correlation exists, but also try to explain the very correlation mechanism theoretically and empirically. Mount, Barrick, and Srauss (1999) claim that individuals with high EI have a clear goal, are achievement oriented, and that allows them to define academic goals that would provide for higher results. Furthermore, individuals with high EI are prone to decisiveness and persistence, and this may stipulate greater commitment towards the said academic goals (Barrick, Mount, \& Strauss, 1993; Tepper, Duffy, \& Shaw, 2001). It is possible that the said self-motivation traits have an influence not just to apply more effort, but also constantly maintain the said efforts in pursuit of academic achievement (Barrick et al., 1993). Individuals with high EI are prone to put off short-term pleasures and concentrate on set goals (Petrides, 2009). They are also characterized by great self-control and can dissociate from tempting stimuli to pursue higher objectives (Fishbach \& Shah, 2006; Trope \& Fishbach, 2005). This is also applicable to pursuit academic achievement. Theoretically it is likely that individuals with high EI are up-front inclined to regulate their own emotions, therefore they are less controlled by negative emotions in the context of academic studies, and this may incite better academic performance (Goetz, Frenzel, Pekrun, \& Hall, 2005; Petrides, 2011).

\section{CONCLUSIONS}

Results of the study importantly show that correlation between academic achievement and emotional intelligence exists. The highest emotional intelligence is of those subjects who are/were excellent students, while the lowest - of poor students. Mathematical and language abilities turned out to be significant indexes of emotional intelligence: it has been determined that subjects who are better at sciences are best at understanding and control of their own emotions, while individuals who are better at languages are more efficient in understanding and control of emotions of other people.

\section{REFERENCES}

Antinienè, D., \& Lekavičienè, R. (2014). Design characteristics of the short version EI-DARL-V1 of original emotional intelligence measurement technique. Education. Physical Training. Sport: Baltic Journal of Sport and Health Sciences, 1, 9-15.

Barchard, K. (2003). Does emotional intelligence assist in the prediction of academic success? Educational and Psychological Measurement, 63(5), 840-858. doi: $10.1177 / 0013164403251333$
Barrick, M. R., Mount, M. K., \& Strauss, J. P. (1993). Conscientiousness and performance of sales representatives: Test of the mediating effects of goal setting. Journal of Applied Psychology, 78, 715-722.

Bjarnason, T. (2000). Grooming for success? The impact of adolescent society on early intergenerational social mobility. Journal of Family and Economic Issues, 21(4), 319-342. doi:10.1023/A:1026476520431 
Codier, E., \& Odell, E. (2014). Measured emotional intelligence ability and grade point average in nursing students. Nurse Education Today, 34, 608-612. doi: http://dx.doi.org/10.1016/j.nedt.2013.06.007

Fallahzadeh, A. (2011). The relationship between emotional intelligence and academic achievement in medical science students in Iran. Procedia - Social and Behavioral Sciences, 30, 1461-1466. doi:10.1016/j. sbspro.2011.10.283

Fayombo, G.A. (2011). Predicting academic achievement using emotional intelligence and gender. Second World Congress on Positive Psychology: Abstracts (pp. 279). Philadelphia.

Ferrando, M., Prieto, M. D., Almeida, L. S., Ferrandiz, C., Bermejo,R.,Lopez-PinaJ.A....Fernandez,M.-C.C.(2010). Trait emotional intelligence and academic performance: Controlling for the effects of IQ, personality, and selfconcept. Journal of Psychoeducational Assessment, 29, 150-159. doi: 10.1177/0734282910374707

Fishbach, A., \& Shah, J. Y. (2006). Self-control in action: Implicit disposition toward goals and away from temptations. Journal of Personality and Social Psychology, 90, 820-832. doi: 10.1037/00223514.90.5.820

Goetz, T., Frenzel, C. A., Pekrun, R., \& Hall, N. (2005). Emotional intelligence in the context of learning and achievement. In R. Schulze, \& R. D. Roberts (Eds.), Emotional intelligence: An international handbook (pp. 233-253). Cambridge, MA: Hogrefer \& Huber.

Lam, L. T., \& Kirby, S. L. (2002). Is Emotional Intelligence an Advantage? An Exploration of the Impact of Emotional and General Intelligence on Individual Performance. The Journal of Social Psychology, 142(1), 133-143.

Lekavičienè, R., \& Antinienè, D. (2014). The construction principles and problems of the long version EI-DARL-V2 original measurement methodology of emotional intelligence. Social Sciences, 2(84), 69-80. doi: http://dx.doi.org/10.5755/j01.ss.84.2.7486

Lillydahl, J. H. (1990). Academic achievement and parttime employment of high school students. Journal of Economic Education, 21, 307-316.

Mavroveli, S., Petrides, K. V., Sangareau, Y., \& Furnham, A. (2009). Exploring the relationships between trait emotional intelligence and objective socio-emotional outcomes in childhood. British Journal of Educational Psychology, 79, 259-272. doi:10.1348/000709908X368848

Mavroveli, S., \& Sánchez-Ruiz, M. J. (2011). Trait emotional intelligence influences on academic achievement and school behaviour. British Journal of Educational Psychology, 81, 112-134. doi: 10.1348/2044-8279.002009

Mount, M. K., Barrick, M. R., \& Strauss, J. P. (1999). The joint relationship of conscientiousness and ability with performance: Test of the interaction hypothesis. Journal of Management, 25, 707-721. doi: 10.1177/014920639902500505

Perera, H. N. \& DiGiacomo, M. (2013). The relationship of trait emotional intelligence with academic performance: A meta-analytic review. Learning and Individual Differences, 28, 20-33. doi:10.1016/j. lindif.2013.08.002

Petrides, K. V. (2011). Ability and trait emotional intelligence. In T. Chamorro-Premuzic, A. Furnham, \& S. von Stumm (Eds.), The Blackwell-Wiley handbook of individual differences (pp. 656-678). New York, NY: Wiley.

Petrides, K. V., Frederickson, N., \& Furnham, A. (2004). The role of trait emotional intelligence in academic performance and deviant behavior at school. Personality and Individual Differences, 36 (2), 277-293. doi:10.1016/S0191-8869(03)00084-9

Petrides, K. V. (2009). Technical manual for the Trait Emotional Intelligence Questionnaires (TEIQue) (1st ed.). London: London Psychometric Laboratory.

Radford, M. (2011). Emotional Intelligence as a Predictor of Nursing Student Success (Doctoral dissertation). Retrieved from Dissertation Abstracts International.

Seipp, B. (1991). Anxiety and academic performance: A meta-analysis. Anxiety Research, 4, 46-53.

Suliman, V. (2010). The relationship between learning styles, emotional social intelligence, and academic success of undergraduate nursing students. Journal of Nursing Research, 18(2), 136-143.

Tepper, B. J., Duffy, M. K., \& Shaw, J. D. (2001). Personality moderators of the relationships between abusive supervision and subordinates' resistance. Journal of Applied Psychology, 86, 974-983.

Trope, Y., \& Fishbach, A. (2005). Going beyond the motivation given: Self-control and situational control over behaviour. In R. R. Hassin, J. Uleman, \& J. A. Bargh (Eds.), The new unconscious (pp. 537-563). New York: Oxford University Press.

Zins, J. E., Weissberg, R. P., Wang, M. C., \& Walberg, H. J. (Eds.). (2004). Building academic success on social and emotional learning: What does the research say? New York: Teachers College Press. 